\title{
A Plant-based Approach to Deficit Irrigation in Trees and Vines
}

\author{
Ken Shackel \\ Department of Plant Sciences, University of California, One Shields Avenue, Davis, CA 95616-8683
}

Additional index words. stem water potential, stress, almond, hull split, stomatal conductance

\begin{abstract}
Field experiments have been performed on grapevine as well as a number of woody tree species (almond, prune, pear, cherry) to determine the relation of plant water potential to a number of indices of plant physiological activity (leaf conductance, vegetative growth, and fruit growth and composition). Horticultural benefits of regulated deficit irrigation (RDI) have been documented in several crops (grapevine, almond, prune, cherries), but management of irrigation to achieve these benefits is difficult without a reliable plant-based measure of stress. Midday stem water potential (SWP) has proven to be a robust, reliable, and practical measure of stress and closely related to physiological responses at the leaf and whole plant level [stomatal conductance $\left(g_{\mathrm{S}}\right)$, vegetative growth, and fruit growth and composition such as soluble solids and fruit color].
\end{abstract}

The nature of plant stress responses, particularly to water-limited conditions, is of fundamental interest to biologists because they are one of the most important adaptations of plant life to terrestrial existence. The study of such responses improves understanding of the mechanisms by which environmental signals are transduced in biological systems. Describing the occurrence and consequences of water stress in plants is also clearly relevant to agricultural research. The substantial limitations to crop productivity that result from reduced water availability have been widely recognized (e.g., Boyer, 1982) and studied for some time (e.g., Kramer, 1974), but there are many contrasting approaches to estimating crop water requirements and the need for irrigation. Most methods used to estimate crop water needs are based on soil or environmental factors, particularly the evapotranspiration (ET) method (e.g., Howell and Meron, 2007), and it is often assumed that replacement of ET is the primary objective of irrigation management. However, crops are biological organisms, and it must be recognized that the purpose of irrigation, similar to all other cultural inputs, is to sustainably improve crop productivity. The soil-plant-atmosphere continuum model (Fig. 1), which forms the basis for our current understanding of plant-water relationships and

Received for publication 13 Sept. 2010. Accepted for publication 22 Oct. 2010.

This work was supported in part by the California Dried Plum (prune) Board, the Almond Board of California, the California Agricultural Experiment Station, and the University of California Cooperative Extension.

This work would not have been possible without the cooperation of many UCCE farm advisor and specialist colleagues: Rick Buchner, Joe Connell, John Edstrom, Allan Fulton, Brent Holtz, Bill Krueger, Bruce Lampinen, Bill Olson, Dave Ramos, Wilbur Reil, Larry Schwankl, Steve Sibbett, and Mario Viveros.

This paper was part of the colloquium "Water Management and Plant Performance in a Changing Climate" held 4 Aug. 2010 at the ASHS Conference, Palm Desert, CA, and sponsored by the Water Utilization and Plant Performance in a Changing Climate (WUM) Working Group.

e-mailkashackel@ucdavis.edu. the responses of plants to water-limited conditions, suggests that plant-based measures such as plant water potential should be the most straightforward indicator of plant water stress and the biological need for irrigation (e.g., Peretz et al., 1984). Plant water potential should measure the integrated effect of soil, plant, and atmospheric conditions on the water availability within the plant itself. The relationship between plant water potential and plant function has been controversial however (e.g., Sinclair and Ludlow, 1985), and hence our understanding of the effects of water stress on plants, and our potential ability to use plant water stress as a tool in irrigation management, is limited. There is evidence in many tree crops (e.g., Boland et al., 1993; Chalmers et al., 1986; Shackel et al., 2000b) that restricted water supply (also referred to as deficit irrigation) can increase water use efficiency and provide horticultural benefits such as higher fruit sugar concentrations. Hence, it is likely that a better plant-based understanding of water stress will lead to improved water management in these crops.

The pressure chamber has been in general use since the 1960s, but neither it nor any of the other methods for measuring water potential (typically leaf water potential) have proven to be reliable or consistent indicators of water stress, particularly under field conditions. An important finding relative to this issue was evidence that stem water potential was better able to detect differences between irrigation regimes than the more commonly used leaf water potential (Garnier and Berger, 1985). We determined that midday SWP was a reliable and consistent measure of stress in prune trees (McCutchan and Shackel, 1992) and have streamlined the methodology (Fulton et al., 2001) and developed SWP as a diagnostic index of water stress across many crops (Shackel et al., 1997, 2000a). We developed a field monitoring tool to measure plant water stress (http://fruitsandnuts.ucdavis.edu/General_ Management/The_Pressure_Chamber,_aka_ The_Bomb.htm), which was commercialized (http://pmsinstrument.com/pump-up.htm) for use in on-farm water management. Based on the Soil-plant-atmosphere (SPAC) model (Fig. 1), the same daily pattern in SWP can be expected for all crops with the midday minimum reaching a value depending on the environmental evaporative demand for fully irrigated crops (Fig. 2) and with further reductions resulting from limitations in soil water availability (Fig. $3)$. In prune, we have used this method to reduce irrigation on the order of $50 \%$ while still maintaining productivity (Shackel et al., 2000b). The key finding of this work is that crops may exhibit horticulturally beneficial responses at mild to moderate levels of water stress (Lampinen et al., 1995, 2001, 2004), and hence we believe that this plant-based approach to irrigation scheduling will allow us to recommend a strategy of RDI that will appeal to growers and also will benefit the environment by reducing water and nitrogen fertilizer leaching below the root zone. Initial work using this method has also been successful in measuring stress in native oak species (Shackel and Gross, 2002) and ornamental roses (Kim et al., 2004). A series of experiments were performed to test for a broad applicability of SWP to water management under field conditions in prunes and almonds and to determine whether SWP had a consistent relation to $g_{\mathrm{S}}$ in almonds under both irrigated and rain-fed (drought) conditions.

\section{MATERIALS AND METHODS}

In all of the studies listed subsequently, values of water potential were measured with the pressure chamber technique on leaves that were enclosed for more than $10 \mathrm{~min}$ to prevent transpiration and allow equilibration with SWP (Fulton et al., 2001). SWP was measured on lower canopy mature leaves that were attached to stems near the trunk or a main scaffold at midday (1300 to $1500 \mathrm{HR}$ local time). These leaves give highly reproducible values for a given tree at any particular time of day (Fulton et al., 2001), and typically the measurement of a single leaf is sufficient to quantify the level of plant water status. Stomatal conductance was measured on the abaxial (lower) surface of upper canopy, recently mature sunlit leaves with a steadystate porometer (Model 1600; LI-COR, Lincoln, NE), with minimal disturbance to the natural position of the leaf. 


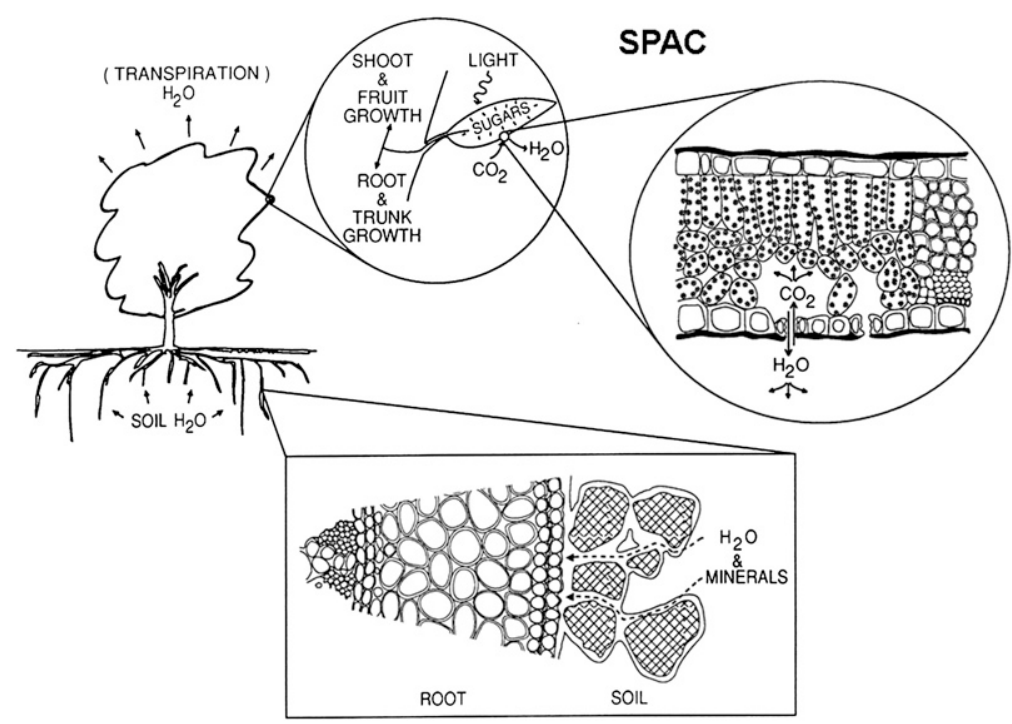

Fig. 1. Water transport through the soil-plant-atmosphere continuum (SPAC). Because the atmosphere is typically less than $100 \%$ relative humidity, water must be lost to obtain carbon dioxide for photosynthesis (upper right). This water loss (transpiration) results in a water tension throughout the plant body, which is used by the root to extract water from the soil (lower right). If the soil is dry, the rate of transpiration is high, or if the ability of the root to absorb water from the soil is compromised, the level of tension in the plant will increase. The level of tension in the stem water potential (SWP) can be measured with the pressure chamber by sampling a non-transpiring (bagged) leaf.

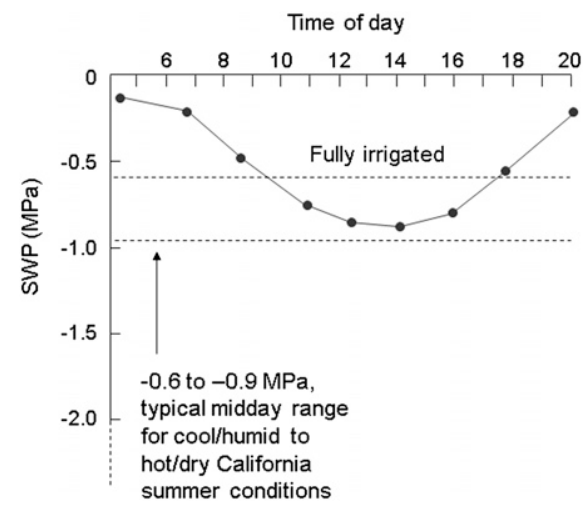

Fig. 2. Typical example of the daily pattern in stem water potential (SWP) for a non-soil-waterlimited (fully irrigated) almond or prune tree. A minimum SWP is reached at midday when the rate of evapotranspiration (ET) is the highest. Horizontal dashed lines indicate the range of midday SWP that is typically observed under summer conditions in the central valley of California.

Prune orchard survey. In 1993, a survey was conducted in 12 commercial prune orchards distributed in the prune-growing areas of California (from Kings County in the south to Tehama County in the north) in a variety of soils (sand to clay) and irrigation system types (flood to drip) in which SWP was measured approximately weekly under normal grower irrigation practices. The purpose of this survey was to test whether the relationship between midday SWP and midday vapor pressure deficit (VPD) reported for "fully irrigated" prunes by McCutchan and Shackel (1992) applied to prunes growing in different regions and on different soil types. Based on McCutchan and Shackel (1992), the

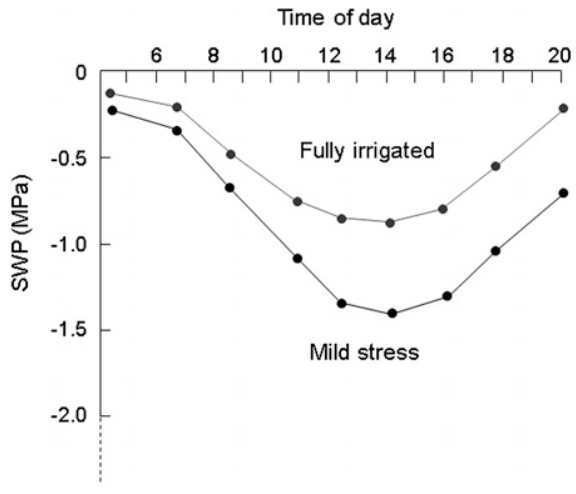

Fig. 3. Example of the daily pattern in stem water potential (SWP), which might be observed for a mildly stressed prune or almond tree compared with a fully irrigated tree.

fully irrigated condition would correspond to a maximum SWP expected under any given environmental condition and hence represent an upper limit in the SWP/VPD relation.

Young almond study. Almond trees of the 'Nonpareil' and 'Carmel' varieties were planted and grown in an experimental orchard in Winters, CA, under three contrasting irrigation regimes (WET, MEDUIM, DRY) for 3 years (1991 to 1993). Irrigation was supplied by under-tree low-volume microsprinklers at twice-weekly intervals for the wet treatment and weekly or less often for the medium and dry treatments. Irrigation amounts and timing were based on maintaining contrasting levels of SWP.

Almond drought study. To test for a relationship between SWP and leaf $g_{\mathrm{S}}$, in 2009, three contrasting deficit irrigation levels were imposed in a mature (older than 15 years old) research almond orchard in Arbuckle, CA.
The objective of this experiment was to cause severe stress in some trees compared with the normal seasonal irrigation of $\approx 1020 \mathrm{~mm}$ applied water; the planned deficit treatments were to receive $0 \mathrm{~mm}, 130 \mathrm{~mm}$, and $250 \mathrm{~mm}$ of irrigation with the $130-\mathrm{mm}$ and $250-\mathrm{mm}$ treatments accomplished by reducing the number and/or size of drip emitters. Hence, the $130-\mathrm{mm}, 250-\mathrm{mm}$, and control irrigation treatments had the same frequency and duration. This site was on a low water-holding capacity soil with trees being irrigated with a single-line drip system; both of these factors contributed to our ability to achieve severe stress under deficit irrigation. To compare the stomatal responses of these trees, particularly in the non-irrigated ( $0 \mathrm{~mm}$, i.e., rainfall only) treatment, the SWP and $g_{\mathrm{S}}$ were measured in two rain-fed almond orchards located $\approx 20$ miles from the Arbuckle site and under similar environmental conditions. In all cases, a single SWP measurement was made for each tree, and four to five measurements of $g_{\mathrm{S}}$ were made with a LI-COR 1600 steady-state porometer on fully exposed, outer canopy leaves and a single average calculated for each tree.

Almond regulated deficit irrigation study. From 2001 to 2004, RDI experiments were performed in commercial almond orchards to test the RDI recommendations of Teviotdale et al. (2001) for deficit irrigation during the period of hull splitting to control hull rot disease, improve harvestability, and allow water savings. In these tests, irrigation was reduced on a site-specific basis, typically a small area comprised of three to four rows of trees, but in some cases, irrigation was reduced to entire irrigation blocks. The criterion for irrigation was to maintain the trees at a target SWP of -1.4 to $-1.8 \mathrm{MPa}$ during the hull split period ( $5 \%$ to $90 \%$ of hulls split, evaluated visually).

\section{RESULTS AND DISCUSSION}

Prune orchard survey. McCutchan and Shackel (1992) found a linear relation between SWP and the air VPD at the time of SWP measurement for field-grown prune trees that were growing in a soil maintained at or above field capacity. The wet soil condition was maintained by daily drip irrigation over the entire soil surface area, and it was hypothesized that the relation between SWP and VPD found under these conditions would represent an upper limit ("baseline") for the relation found under normal production conditions, which was found to be the case (Fig. 4). Each point in Figure 4 represents a single tree value, which is the reason why points are aligned in vertical groups, because all the trees measured on one date and at one location were under the same VPD condition. A few individual points were slightly above (by $\approx 0.1 \mathrm{MPa}$ ) the baseline relation, but most points were at or below the baseline, which is consistent with an "Ohms Law" analogy of water transport in plants (i.e., flow $=$ water potential difference $\times$ conductance). In this case, the water potential difference would be between the soil and the stem such that the SWP of trees under field conditions would be determined both by a soil 
moisture effect, which would determine the initial (effective soil) water potential, and a VPD effect, which would include both pathway conductance as well as flow (transpiration) effects. Assuming a constant conductance and a linear relation between VPD and transpiration (flow), SWP would be expected to decline linearly with VPD under non-soil-water-limited conditions (i.e., the baseline relation) and further decrease as soil water potential decreased, consistent with the pattern observed under production conditions (Fig. 4).

Young almond study. In an independent experiment, the predicted baseline SWP for prunes was also a good predictor for the SWP of first-year almonds that were maintained under a "wet" condition (biweekly irrigation using a microsprinkler system, which wet essentially all of the root zone), except during August, when the observed SWP values were somewhat below those predicted by the baseline (Fig. 5). After this time, however, irrigation was increased to well over estimated ETc (data not shown), and the observed SWP returned to the baseline (Fig. 5). This as well as subsequent SWP measurements in prune and almond has demonstrated that the baseline approach to predicting the SWP of fully irrigated (non-soil-water-limited) trees is robust and that the equation reported by McCutchan and Shackel (1992) may apply broadly to a number of Prunus species. The data shown in Figure 5 also demonstrate the ability of SWP to clearly and consistently differentiate irrigation treatments.

Almond drought study. An important issue both for irrigation studies as well as studies in plant stress physiology is the shape of the relation between resource availability and plant productivity. It is commonly assumed that plants respond to increases in resource availability by exhibiting a "plateau" (no further increase in plant performance) above a particular threshold level of resource availability such as for yield and nitrogen (e.g., Loomis and Connor, 1992). This concept has also been applied in describing $g_{\mathrm{S}}$ as having a "threshold" response to water potential (Turner, 1974), and in this case, water potential would correspond to the level of resource. In both cases, the responses are considered "diminishing returns" responses in that the change in response for a unit change in resource is largest when the resource is most limiting and becomes progressively smaller with further increases in the resource. However, the relation between $g_{\mathrm{S}}$ and SWP that was found in almond had the opposite property, namely, that the increase in conductance for a unit change in SWP was progressively larger as SWP increased (Fig. 6). If other physiological responses of almonds to water availability have a similar shape to that found for $g_{\mathrm{S}}$, then large productivity gains might be found with increases in irrigation rather than a linear relation (e.g., Dehghanisanij et al., 2009). It is particularly interesting to note that both rain-fed and irrigated trees had similar levels of $g_{\mathrm{S}}$ for the same level of SWP, indicating that growth under rain-fed conditions

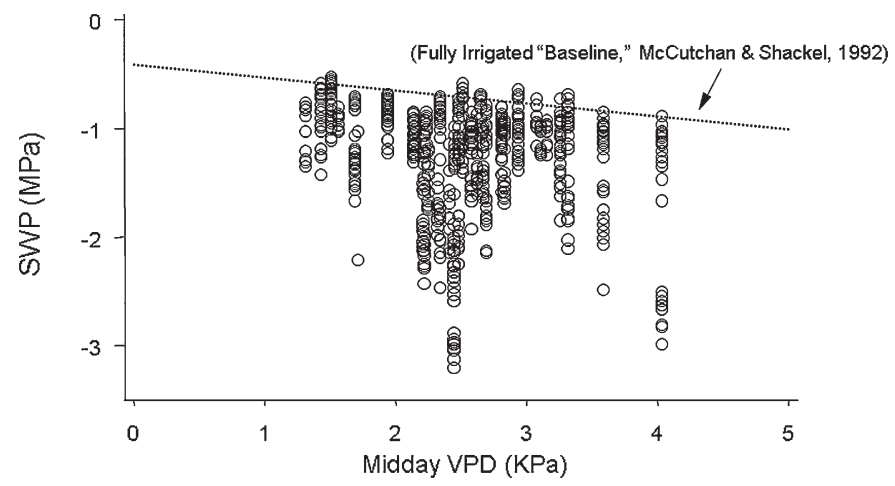

Fig. 4. Summary of all measurements of midday stem water potential (SWP) made on individual trees (data points) as a function of air vapor pressure deficit (VPD) for the prune orchard survey compared with the baseline relation reported by McCutchan and Shackel (1992) for fully irrigated prune trees $(\mathrm{SWP}=-0.12 * \mathrm{VPD}-0.41)$.

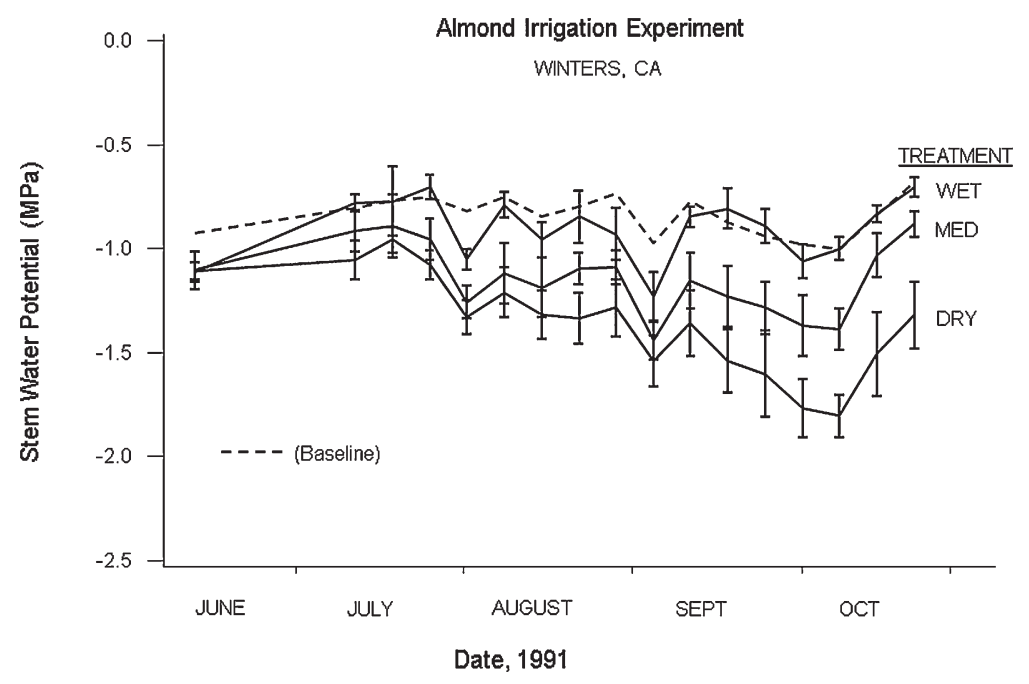

Fig. 5. Midday stem water potential (SWP) observed under three irrigation treatments (wet, medium, and dry) in the young almond study. Means are shown $\pm 2 \mathrm{SE}(\mathrm{N}=)$. Also shown is the baseline SWP expected for fully irrigated trees, obtained from the midday air vapor pressure deficit, as shown in Figure 4.

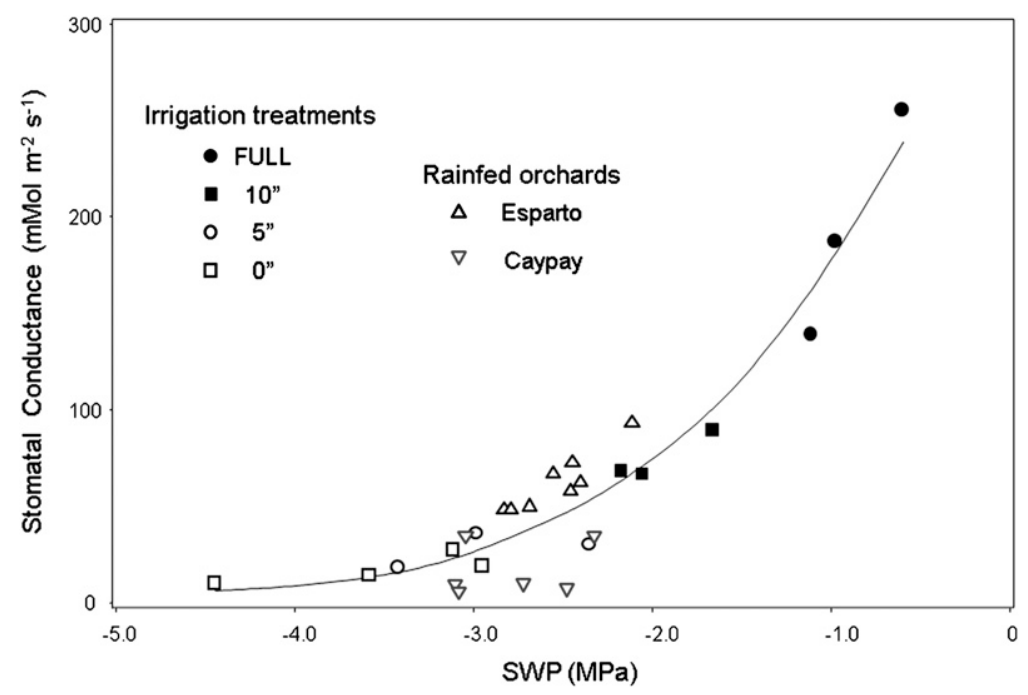

Fig. 6. Midday stomatal conductance $\left(g_{\mathrm{S}}\right)$ for trees in the almond drought study, including contrasting irrigation conditions in experimental plots in Arbuckle, CA, and rain-fed almonds in two additional locations (Esparto and Capay, CA) as a function of midday stem water potential (SWP). Each point is the average of four to six leaf conductance measurements and one SWP measurement per tree. 
may not result in a substantial acclimation of stomatal opening to lower levels of SWP.

Almond regulated deficit irrigation study. In addition to its usefulness in physiological studies, SWP has been successfully used as a basis for irrigation management in prune (Shackel et al., 2000b) and for the identification of irrigation-related problems in other tree crops. In 2000, SWP measurements were made on trees in different locations of an almond orchard that exhibited substantial differences in the timing and progress of hull split. A substantial delay in hull split was observed on trees in an east location, compared with trees in a west location (Table 1), with these locations corresponding to the presence of a silt and a gravel soil, respectively (data not shown). Such variation in the timing of hull split is undesirable because it makes the efficient scheduling of preharvest and harvest operations more difficult and costly. Based on the results of Teviotdale et al. (2001), we hypothesized that this delay in hull split on the east soil trees would be associated with higher levels of available water and higher SWP, and this was found to be the case (Table 1). According to the grower, the substantial delay in hull split on the east soil occurred across all varieties in every year, and beginning in 2001, RDI was managed on a soil-specific basis to achieve a target SWP of -1.4 to $-1.8 \mathrm{MPa}$ during the hull split period for all trees. From 2001 to 2003 , the progression of hull split was identical on the different soil types (Table 2), and over these years, RDI resulted in a seasonal water savings of $\approx 50 \%$ on the east soil compared

Table 1. Progression of hull splitting (percent split hulls) observed over time for 'Carmel' almond trees on east and west sides of the same almond orchard and the average stem water potential (SWP) measured in these trees over the same time period before any regulated deficit irrigation treatments. ${ }^{2}$

\begin{tabular}{lccccccc}
\hline & Avg SWP & \multicolumn{6}{c}{ Date, 2000 } \\
\cline { 3 - 8 } Side & (MPa) & 10 Aug. & 16 Aug. & 22 Aug. & 31 Aug. & 6 Sept. & 14 Sept. \\
\hline East & -0.84 & $0 \%$ & $0 \%$ & $5 \%$ & $13 \%$ & $32 \%$ & $40 \%$ \\
West & -1.41 & $4 \%$ & $23 \%$ & $60 \%$ & $83 \%$ & $85 \%$ & $91 \%$ \\
\hline
\end{tabular}

${ }^{\mathrm{z}}$ The east/west difference in the progression of hull split was the same in all varieties.

Table 2. Progression of hull splitting (percent split hulls) observed over time for 'Nonpareil' almond trees on east and west sides of the same orchard for the almond regulated deficit irrigation study when irrigated differentially to maintain the stem water potential in the -1.4 to $-1.8 \mathrm{MPa}$ range during the hull split period.

\begin{tabular}{lccccc}
\hline & \multicolumn{5}{c}{ Date, 2001 } \\
\cline { 2 - 6 } Side & 13 July & 20 July & 27 July & 1 Aug. & 13 Aug. \\
\hline East & $2 \%$ & $20 \%$ & $45 \%$ & $70 \%$ & $100 \%$ \\
West & $2 \%$ & $55 \%$ & $75 \%$ & $100 \%$ \\
& & & & \\
& & & Date, 2003 & 22 Aug. \\
& & & 7 Aug. & 15 Aug. & $100 \%$ \\
East & 29 July & $96 \%$ & $100 \%$ & $100 \%$ \\
\cline { 3 - 6 } West & $29 \%$ & $88 \%$ & $100 \%$ & \\
\hline
\end{tabular}

Table 3. Yields (pounds nutmeats per acre) recorded over 4 years in almond regulated deficit irrigation (RDI) grower trial sites comparing normal (grower) irrigation with RDI.

\begin{tabular}{lcccc}
\hline & \multicolumn{4}{c}{ Yr and number of sites } \\
\cline { 2 - 5 } Irrigation Treatment & $2001(2$ sites $)$ & $2002(7$ sites $)$ & $2003(7$ sites $)$ & 2004 (7 sites) \\
\hline Grower & 2400 & 3170 & 2860 & 2650 \\
RDI & 2430 & 3080 & 2660 & 2680 \\
\hline
\end{tabular}

canopy temperature and canopy spectral characteristics (e.g., Wang et al., 2009).

\section{Literature Cited}

Boland, A.M., P.D. Mitchell, P.H. Jerie, and I. Goodwin. 1993. The effect of regulated deficit irrigation on tree water use and growth of peach. J. Hort. Sci. 68:261-274.

Boyer, J.S. 1982. Plant productivity and the environment. Science 218:443-448.

Chalmers, D.J., G. Burge, P.H. Jerie, and P.D Mitchell. 1986. The mechanism of regulation of 'Bartlett' pear fruit and vegetative growth by irrigation withholding and regulated deficit irrigation. J. Amer. Soc. Hort. Sci. 111:904-907.

Dehghanisanij, H., M.M. Nakhjavani, A.Z. Tahiri, and H. Anyoji. 2009. Assessment of wheat and maize water productivities and production function for cropping system decisions in arid and semiarid regions. Irrigation and Drainage 58:105-115

Fulton, A., R. Buchner, B. Olson, L. Schwankl, C. Giles, N. Bertagnia, J. Walton, and K. Shackel. 2001. Rapid equilibration of leaf and stem water potential under field conditions an almonds, walnuts and prunes. HortTechnology 11:609-615

Garnier, E. and A. Berger. 1985. Testing water potential in peach trees as an indicator of water stress. J. Hort. Sci. 60:47-56.

Howell, T.A. and M. Meron. 2007. Irrigation scheduling. In: Lamm, F.R., J.E. Ayars, and F.S. Nakayama (eds.). Microirrigation for crop production. Elsevier.

Kim, S.H., K.A. Shackel, and J.H. Lieth. 2004 Bending alters water balance and reduces photosynthesis of rose shoots. J. Amer. Soc. Hort. Sci. 129:896-901

Kramer, P.J. 1974. Fifty years of progress in water relations research. Plant Physiol. 54:463-471.

Lampinen, B.D., K.A. Shackel, S.M. Southwick, B. Olson, J.T. Yeager, and D. Goldhamer. 1995. Sensitivity of yield and fruit quality of french prune to water deprivation at different growth stages. J. Amer. Soc. Hort. Sci. 120:139-147.

Lampinen, B.D., K.A. Shackel, S.M. Southwick, and W.H. Olson. 2001. Deficit irrigation strategies using midday stem water potential in prune. Irrig. Sci. 20:47-54.

Lampinen, B.D., K.A. Shackel, S.M. Southwick, W.H. Olson, and T.M. DeJong. 2004. Leaf and canopy level photosynthetic responses of French prune (Prunus domestica L. 'French') to stem water potential based deficit irrigation. J. Hort. Sci. Biotechnol. 79:638-644.

Loomis, R.S. and D.J. Connor. 1992. Crop ecology: Productivity and management in agricultural systems. Cambridge University Press, New York, NY.

McCutchan, H. and K.A. Shackel. 1992. Stemwater potential as a sensitive indicator of water stress in prune trees (Prunus domestica L. cv. French). J. Amer. Soc. Hort. Sci. 117:607-611.

Naor, A. 2006. Irrigation scheduling and evaluation of tree water status in deciduous orchards. Hort. Rev. (Amer. Soc. Hort. Sci.) 32:111-165.

Peretz, J., R.G. Evans, and E.L. Proebsting. 1984. Leaf water potentials for management of high frequency irrigation on apples. Trans. ASAE 27:437-442.

Shackel, K.A., H. Ahmadi, W. Biasi, R. Buchner, D. Goldhamer, S. Gurusinghe, J. Hasey, D. Kester, B. Krueger, B. Lampinen, G. McGourty, W. Micke, E. Mitcham, B. Olson, K. Pelletrau, H. Philips, D. Ramos, L. Schwankl, S. Sibbett, R. Snyder, S. Southwick, M. Stevenson, M. Thorpe, S. Weinbaum, and J. Yeager. 1997. Plant water 
status as an index of irrigation need in deciduous fruit trees. HortTechnology 7:23-29.

Shackel, K. and R. Gross. 2002. Using midday stem water potential to assess irrigation needs of landscape valley oaks. USDA Forest Service Gen. Tech. Rep. PSW-GTR-184. p. 397-402.

Shackel, K., B. Lampinen, S. Sibbett, and W. Olson. 2000a. The relation of midday stem water potential to the growth and physiology of fruit trees under water limited conditions. Acta Hort. 537:425-430.
Shackel, K., B. Lampinen, S. Southwick, D. Goldhamer, W. Olson, S. Sibbett, W. Keueger, J. Yeager, and D. Goldhamer. 2000b. Deficit irrigation in prunes: Maintaining productivity with less water. HortScience 35:30-33.

Sinclair, T.R. and M.M. Ludlow. 1985. Who taught plants thermodynamics? The unfulfilled potential of plant water potential. Aust. J. Plant Physiol. 12:213-217.

Teviotdale, B.L., D.A. Goldhamer, and M. Viveros. 2001. Effects of deficit irrigation on hull rot disease of almond trees caused by Monilinia fructicola and Rhizopus stolonifer. Plant Dis. 85:399-403.

Turner, N.C. 1974. Stomatal behavior and water status of maize, sorghum, and tobacco under field conditions. Plant Physiol. 53:360-365.

Wang, J., T.W. Sammis, V.P. Gutschick, M. Gebremichael, and D.R. Miller. 2009. Sensitivity analysis of the Surface Energy Balance Algorithm for Land (SEBAL). ASABE Transactions. 52:801-811. 